\title{
INFLUENCE DU TRAITEMENT THERMIQUE DU LAIT SUR LA DÉNATURATION DES PROTÉINES DU LACTOSÉRUM
}

\author{
par \\ W. DAMICZ, J. BUDSLAWSKI et K. POGORZELSKI \\ Laboratoire de Chimie du Lait et des Produits Laitiers
à l'Ecole supérieure d'Agriculture, Olsztyn (Pologne)
}

Le lait en poudre et le lait concentré remplacent de plus en plus le lait liquide dans la nutrition des enfants et des adultes. La valeur nutritive de ces produits est fortement influencée par le traitement thermique du lait au cours de leur fabrication. A part les enzymes et certaines vitamines présentes dans le lait, les composants les plus sensibles à l'action de la chaleur sont les protéines du lactosérum qui, pendant la pasteurisation, la concentration ou bien le séchage du lait, sont l'objet de dénaturations partielles ou même totales. Ceci se fait, entre autres, par une interaction caséine-protéines du lactosérum, ou bien protéines-lactose $[1,2]$, ou d'une autre manière.

Damicz [3, 4], dans une étude récente, a montré les modifications des protéines du lactosérum sous l'action de la chaleur dans du lait traité à différentes températures. De même Wegelin [in 5] dans du lait en poudre, Schulte et Müller [6] et Roulet et al. [7] dans du lait stérilisé, du lait concentré et en poudre, ont étudié cette question sous divers aspects. Nous avons cherché dans cette étude à suivre des changements qualitatifs et quantitatifs des protéines du lactosérum dans du lait traité thermiquement lors de différents processus de fabrication, soit du lait de consommation, soit du lait concentré, soit encore du lait en poudre.

\section{I. - Matériel et techniques}

Nos recherches ont porté sur le lait cru de grand mélange (A) (10 échantillons), le lait de consommation (B) (11 échantillons), la poudre de lait entier Spray (C) (11 échantillons), la poudre de lait écrémé Spray (D) (8 échantillons), la poudre de lait écrémé Hatmaker (E) (11 échantillons), le lait de grand mélange bouilli (F) (11 échantillons) et le lait concentré non sucré (G) (10 échantillons). Les poudres de lait et les laits concentrés ont été reconstitués de façon à disposer d'un produit liquide contenant autant de matière sèche qu'un lait cru de grand mélange. Chaque échantillon ainsi obtenu était dégraissé par centrifugation et on en précipitait la caséine, au point isoélectrique, à l'aide d'une solution d'acide oxalique à 10 p. 100 . Le liquide surnageant après centrifugation 
à la suite de la précipitation de la caséine constituait ainsi un lactosérum qui, lyophilisé, a servi aux recherches.

On déterminait l'azote total du lactosérum selon Kjeldahl et on procédait au partage des protéines par voie électrophorétique sur papier Whatman $n^{0} 3$ dans les conditions ci-après [3] : tension: $2 \mathrm{~V} / \mathrm{cm}$ de longueur de bande du papier; tampon : véronal-acétate sodique, $p \mathrm{H} 8,6$ et force ionique 0,1 [8]; durée : $18 \mathrm{~h}$.

On dissolvait $1,5 \mathrm{~g}$ de lactosérum lyophilisé dans $5 \mathrm{ml}$ d'eau distillée; on déposait $0,04 \mathrm{ml}$ de cette solution sur une bande de papier de $6 \times 45 \mathrm{~cm}$, saturée du tampon. Après séparation électrophorétique des protéines, on colorait une partie des bandes de papier, desséchées, au bleu de bromophénol et, la seconde partie, à la ninhydrine en solution acétone à $0,2 \mathrm{p} .100$ [9]. Les bandes de papier colorées au bleu de bromophénol, desséchées et découpées ont été éluées avec une solution du carbonate sodique à 2 p. 100 dans du méthanol à 50 p. 100 [3]. On déterminait ensuite la densité optique (D.O.) de l'éluat contre une solution de comparaison constituant un éluat de la partie non colorée du papier, avec un spectrophotomètre à $600 \mathrm{~m} \mu$. de longueur d'onde et $1 \mathrm{~cm}$ d'épaisseur de la couche. On calculait le pourcentage de fractions protéiques séparées par électrophorèse sur papier par rapport à la somme de D.O. On calculait les changements quantitatifs des fractions protéiques par rapport aux quantités respectives des fractions du lait cru ; on déterminait ainsi le degré de dénaturation des protéines :

$$
\mathrm{x}=100-\frac{\mathrm{DOt} \cdot 100}{\mathrm{DOs}}
$$

où : $\mathrm{x}=$ degré de dénaturation en p. 100 ;

DOt $=$ densité optique de la fraction étudiée ;

DOs $=$ densité optique de la fraction respective du lait cru.

\section{II. - Résultats et discussion}

Les résultats de nos recherches sont représentés sur la figure 1 et sur les tableaux I et II. Comme base de comparaison des changements qualitatifs et quantitatifs dans les protéines du lactosérum des divers laits on a pris les résultats moyens des électrophorèses réalisées du lactosérum provenant de laits crus de mélange (A). Les résultats obtenus pour ces lactosérums sont en accord en général avec ceux obtenus par l'un de nous $[3,4]$ dans les recherches antérieures et par d'autres auteurs $[10,11,12,13]$.

Sur la quantité globale des composés azotés contenus dans le lactosérum des divers laits on peut juger d'après la teneur des lactosérums en azote total (tableau I). On notera la plus haute teneur en azote total dans le lactosérum du lait oru (1,68 p. 100). et la plus basse dans le lactosérum du lait bouilli $(0,73$ p. 100), 
La teneur d'autres lactosérums en azote total était, en ordre décroissant, la suivante : poudre de lait écrémé Spray (1,59 p. 100), lait de consommation (1,52 p. 100), poudre de lait entier Spray $(1,29$ p. 100), poudre de lait écrémé Hatmaker $(1,24$ p. 100) et lait concentré (1,01 p. 100). On voit done que la chaleur exercée sur le lait dans les différents processus de fabrication dénature une partie des protéines du lactosérum.

L'électrophorèse, sur papier, de lactosérum A (fig. 1) montre cinq fractions qui se colorent au bleu de bromophénol et à la ninhydrine, identifiées comme sérum-albumine, $\beta$-lactoglobuline, $\alpha$-lactalbumine et immuno-globulines (pseudo-globuline et euglobuline, resp. fractions 4 et 5 ) et trois fractions qui se colorent à la ninhydrine et ne se colorent pas au bleu de bromophénol, marquées par nous par les lettres a, b, c et que l'on n'a pas pu identifier.

Sur la figure 1 on remarque de grandes différences entre les diverses électrophorèses des protéines du lactosérum, ce qui reste en rapport avec les conditions thermiques du traitement du lait au cours de la fabrication de divers produits laitiers étudiés.

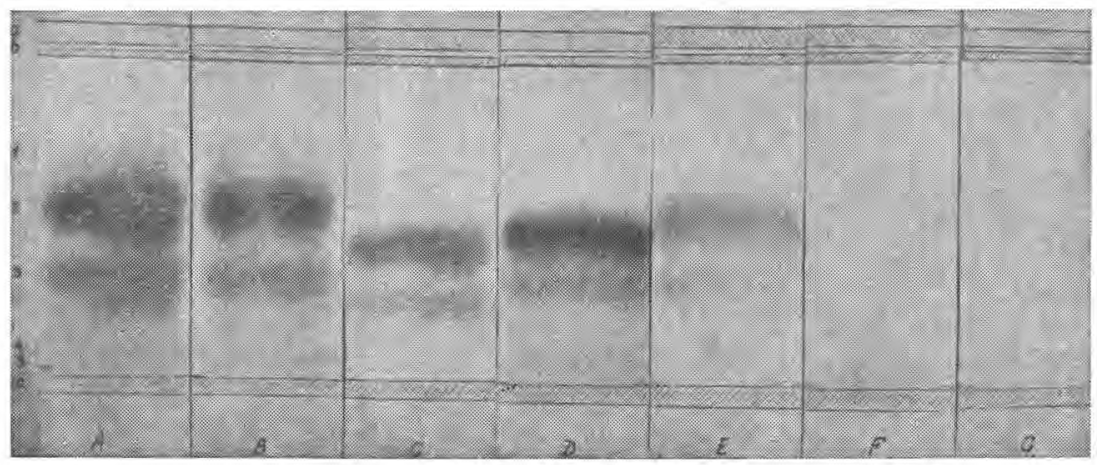

Fig. 1. - Electrophorèse sur papier de protéines de différents types de lactosérum.

Dans le lait de consommation qui a été pasteurisé à $75^{\circ} \mathrm{C}$ pendant 15 secondes, on remarque déjà des changements dans les protéines, à savoir, une diminution, par rapport au lactosérum A, de la teneur en sérum-albumine, $\beta$-lactoglobuline et immunoglobulines, l' $\alpha$-lactalbumine étant inchangée (cf. tabl. I et II). Les plus grands changements que montre le lactosérum du lait bouilli (F) sont la dénaturation complète de la sérum-albumine et de la $\beta$-lactoglobuline et une diminution considérable de la teneur en $\alpha$-lactalbumine et immuno-globulines. Il en est de même avec du lait concentré, où la dénaturation complète a 
touché en outre l' $\alpha$-lactalbumine; par contre on y remarque la présence de deux nouvelles, peu visibles, fractions se colorant au bleu de bromophénol, marquées par nous avec des lettres $\mathrm{X}$ et $\mathrm{Z}$, dont la première a une mobilité électrophorétique plus petite que celle de la $\beta$-lactoglobuline et la seconde plus grande que celle de sérum-albumine (cf. tabl. I).

Parmi les poudres de lait étudiées, on observe les plus petits changements dans les protéines du lactosérum de lait écrémé en poudre Spray (D), néanmoins ici aussi on voit une diminution de près de 60 p. 100 de la teneur en sérum-albumine et de près de 41 p. 100 en immuno-globulines. On note de plus grands changements dans la poudre de lait entier Spray (C) et les plus grands dans la poudre de lait écrémé Hatmaker (E) où a été dénaturée, entièrement la sérum-albumine, et près de 60 p. 100 de la $\beta$-lactoglobuline.

Toutes les préparations d'électrophorèse colorées à la ninhydrine ont montré, en plus, trois fractions ( $a, b, c)$ qui ne se colorent pas au bleu de bromophénol; parmi ces fractions il y en a une (c) qui possède une faible mobilité électrophorétique, très voisine de celle des immuno-globulines, et les deux autres ( $a$ et b) qui, au contraire, possèdent une mobilité électrophorétique dépassant de beaucoup celle de la sérum-albumine. Ces fractions sont présentes à des taux différents dans les lactosérums de laits traités thermiquement, tandis que dans le lait cru elles sont à peine visibles. Les fractions les plus fortement colorées ont montré les électrophorèses des sérums de lait bouilli (F) et de lait concentré (G).

Les résultats obtenus sont semblables à ceux publiés par Schulte et Müller [6] qui, utilisant la même technique, mais colorant les bandes de papier uniquement à la ninhydrine, ont montré dans le lactosérum des laits concentré et stérilisé la dénaturation complète des fractions de sérum-albumine, $\beta$-lactoglobuline et $\alpha$-lactalbumine avec une forte coagulation des immuno-globulines.

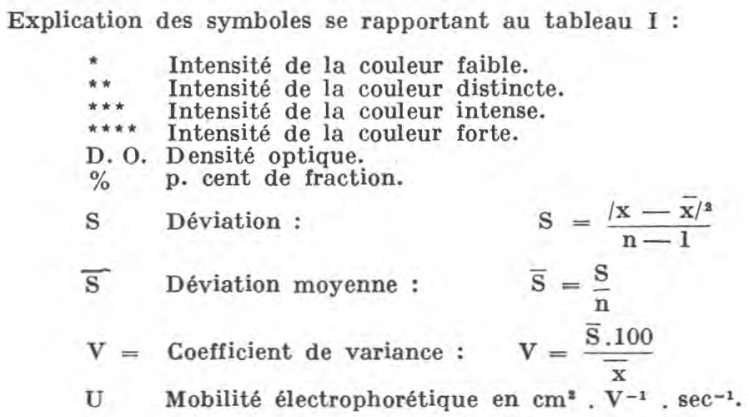


TABLEAU I

PROPORTION DES DIFFÉRENTES FRACTIONS PROTÉIOUES ISOLÉES PAR ÉLEGTROPHORÈSE SUR PAPIER DANS LES SEPT TYPES DE LACTOSÉRUM

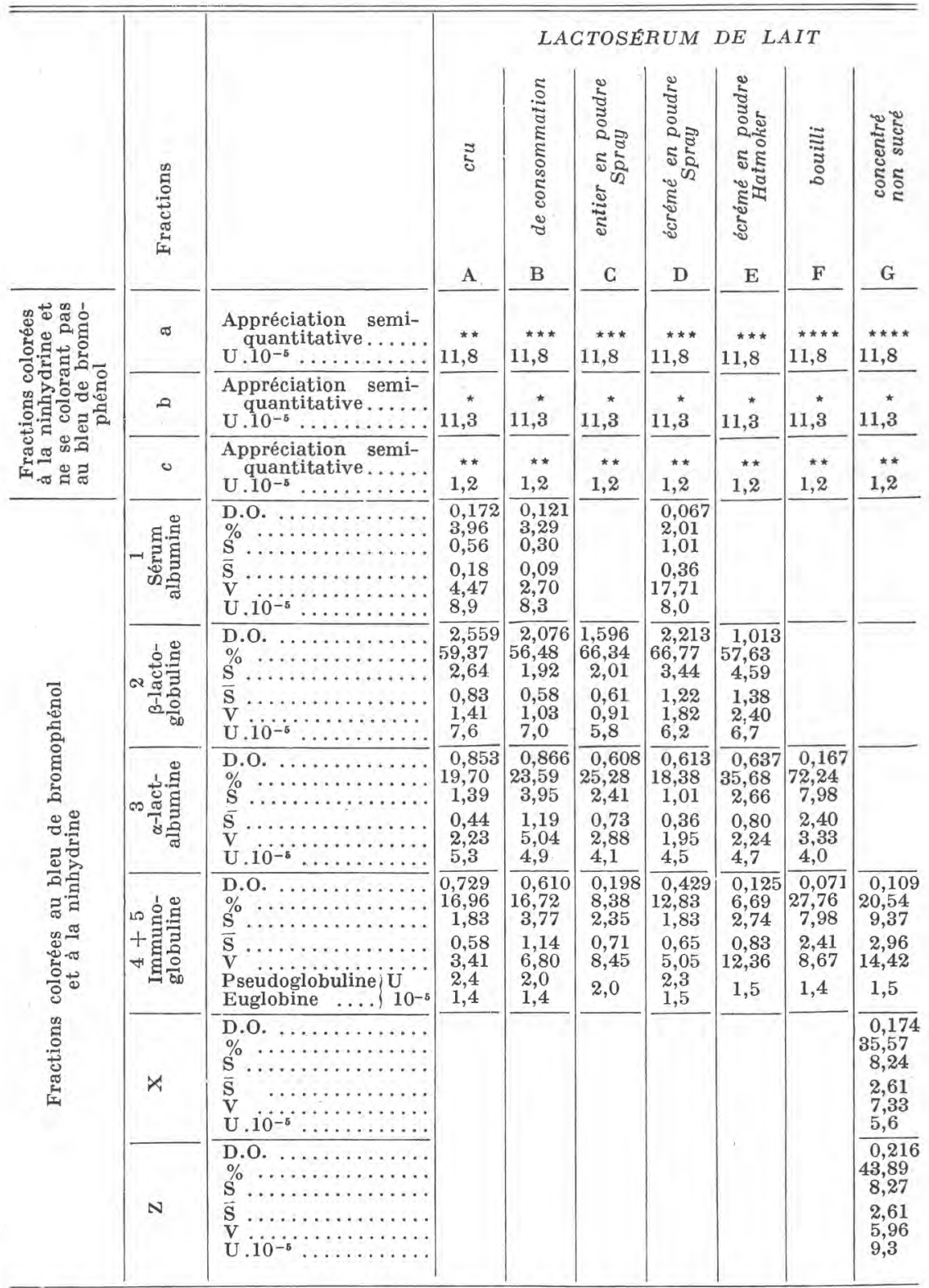

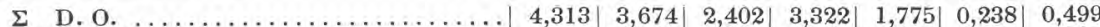

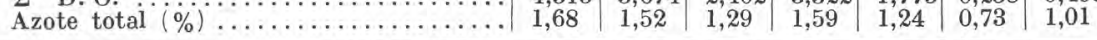


De même, dans la poudre de lait écrémé Hatmaker, ces Auteurs ont constaté la dénaturation de la sérum-albumine et une forte diminution des immuno-globulines et de la $\beta$-lactoglobuline. Dans la poudre de lait écrémé Spray, la dénaturation des protéines était plus faible.

Les fractions les plus mobiles, a et b, semblables à celles désignées par Schulte et Müller $[6,11]$ comme composants I et II, sont vraisemblablement des protéoses issues de la dégradation des protéines.

En comparant nos résultats avec ceux de Roulet et al. [7] on n'a pas pu constater de corrélation distincte entre, d'une part, la diminution des différentes fractions protéiques, sauf pour les immuno-globulines et la sérum-albumine, et, d'autre part, diminution des lignes de précipitation.

\section{Conclusions}

Les recherches réalisées montrent que le plus haut degré de dénaturation des protéines du lactosérum a lieu dans le lait bouilli, c'est-à-dire dans celui qui, dans les conditions de l'expérience, était soumis au plus rigoureux régime thermique. De même, la dénaturation des protéines était bien avancée dans le lactosérum du lait concentré, où, comme on sait, la température d'évaporation de l'eau n'est pas très haute mais où la durée de son action sur les protéines est prolongée.

Parmi les laits en poudre e'est celui qui est produit sur les cylindres (Hatmaker), dont les protéines du lactosérum sont les plus dénaturées. Le lait pasteurisé dont le régime n'est pas trop rigoureux montre le plus faible changement dans les protéines du lactosérum. Enfin, parmi les protéines, c'est la $\beta$-lactoglobuline qui est la plus stable devant l'action de la température.

\section{Summary}

The investigation which have been carried out showed that the denaturation of the whey proteins through heating was the greatest in boiled milk, and then, in decreasing series, in concentrate milk, in roller-dried milk, in spray-dried milk, and was weak at last in pasteurized milk.

The globulin $\beta$ is the stablest among proteins.

\section{RÉFÉRENCES BIBLIOGRAPHIQUES}

[1] H. A. Ntailianas et F. H. Grimbleby. XVIe Congrès Int. de Laiterie, $1962, B, 1033$.

[2] H. A. Ntailianas et F. H. Grimbleby. XVIe Congrès Int. de Laiterie, 1962, B, 1071 . 
TABLEAU II

TENEUR DE DIFFÉRENTS TYPES DE LACTOSÉRUM EN PROTÉINES ISOLEES PAR ÉLECTROPHORÈSE SUR PAPIER PAR RAPPORT AUX PROTÉINES DU LAIT CRU

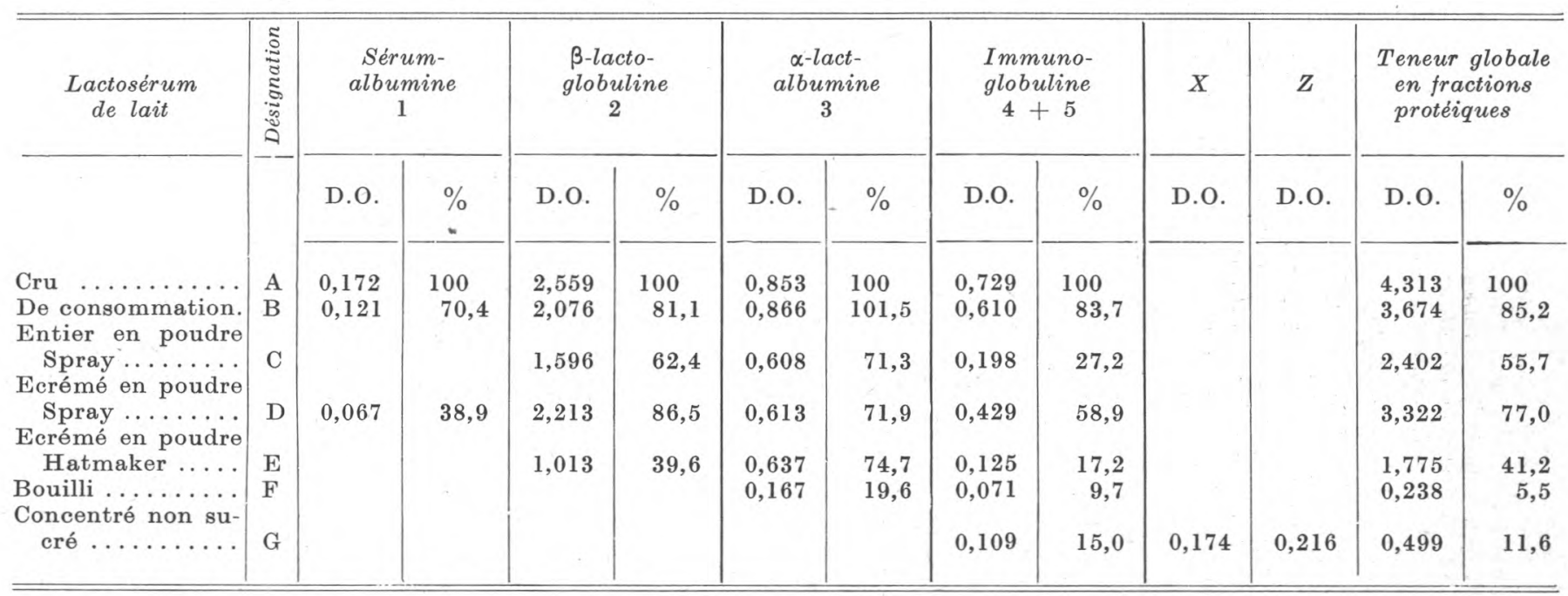


[3] W. Damicz, Zeszyty Nauk. WSR Olsztyn, 1961, [11], 83.

[4] W. Damicz, Zeszyty Nauk, WSR Olsztyn, sous presse.

[5] H. Frehse et H. Fink. Fette-Seifen-Anstr., 1958, [60], 283.

[6] K. E. Schulte et F. MüLler. Milchwissenschaft, 1955, [10], 270.

[7] D. L. A. Roulet et al. Milchwissenschaft, 1961, [16], 415.

[8] F. Cramer. Papierchromatographie. Verlag Chemie, Weinheim-Bergstr., $1958,79$.

[9] I. Sмгтн. Chromatographic and electrophoretic techniques. Vol. II, Zone electrophoresis. William Heinemann. Medical Books Ltd. London, 1960, 27.

[10] B. L. Larson et G. D. Rolleri. J. Dairy Sci., 1955, [38], 351.

[11] K. E. Schulte et F. MÜLler. Milchwissenschaft, 1955, [10], 90.

[12] U. Weigt. Milchwissenschaft, 1959, [14], 61.

[13] E. A. Jdanova et I. N. Vlodavets. Biochimia, 1959, [24], 398. 